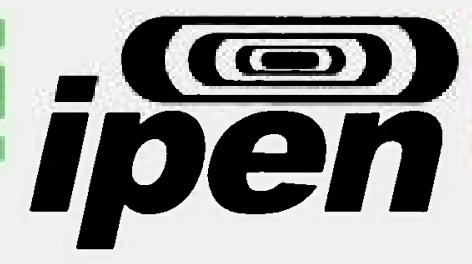

AUTARQUIA ASSOCIADA À UNIVERSIDADE DE SÃO PAULO

\title{
DESENVOLVIMENTO DE REAGENTE LIOFILIZADO DE GLUCOHEPTONATO - ESTANHO PARA MARCAÇÃO DE LEUCÓCITOS COM TECNÉCIO-99m IN VITRO
}

ROSEMEIRE FAGUNDES NASCIMENTO

Dissertação apresentada como parte dos requisitos para obtenção do Grau de Mestre em Ciências na Área de Tecnologia Nuclear - Aplicações.

Orientadora:

Dra. Elaine Bortoleti de Araújo 


\section{ipen}

AUTARQUIA ASSOCIADA À UNIVERSIDADE DE SÃo PAULO

\section{DESENVOLVIMENTO DE REAGENTE LIOFILIZADO DE GLUCOHEPTONATO -ESTANHO PARA MARCAÇÃO DE LEUCÓCITOS COM TECNÉCIO-99 m IN VITRO}

ROSEMEIRE FAGUNDES NASCIMENTO

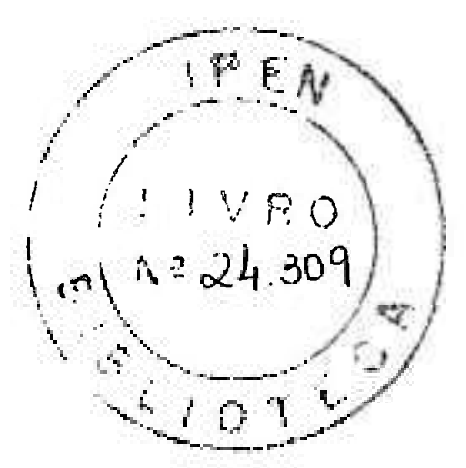

DISSERTAÇ̃̃O APRESENTADA COMO PARTE DOS REQUISITOS PARA OBTENÇÃO DO GRAU DE MESTRE EM CIÊNCIAS NA ÀREA DE TECNOLOGIA NUCLEAR- APLICAÇÕES

ORIENTADORA:

Dra. Elaine Bortoleti de Araújo

SÃO PAULO

2007 


\section{AGRADECIMENTOS}

Ao Instituto de Pesquisas Energéticas e Nucleares e, em particular, ao Centro de Radiofarmácia pela oportunidade da realização deste trabalho.

À Dra Elaine Bortoleti de Araújo pela orientação, paciência e amizade.

Ao Hospital Geral de São Paulo, na pessoa do seu diretor, Coronel médico Sidnei Gomes, pela colaboração.

A todos os militares, doadores voluntários que colaboraram na realização deste trabalho.

Aos amigos e doadores voluntários do Laboratório de Urgência HCFMUSP.

À Dra Denise Fungaro, do Centro Químico e Meio Ambiente - IPEN , pelo apoio e amizade .

Aos funcionários do Centro de Radiofarmácia e a todos que direta ou indiretamente colaboraram..

Ao Centro de Medicina Nuclear, da Faculdade de Medicina da Universidade de São Paulo, na pessoa de Dr. Fábio Luiz Navarro Marques, pela valiosa contribuição na realização das imagens cintilográficas.

Aos pesquisadores, técnicos, bolsistas e estagiários pelo agradável convívio e incentivo durante todo este trabalho. 


\title{
RESUMO
}

\section{DESENVOLVIMENTO DO REAGENTE LIOFILIZADO DE}

\section{GLUCOHEPTONATO-ESTANHO PARA MARCAÇÃO DE LEUCÓCITOS}

\author{
COM ${ }^{99 \mathrm{~m}}$ TC IN VITRO
}

\section{Rosemeire Fagundes Nascimento}

O estudo de processos inflamatórios e infecciosos em Medicina Nuclear apresenta grande relevância para a clínica médica diagnóstica. Enquanto em alguns casos o diagnóstico é óbvio, baseado na história clínica e exame físico do paciente, em outros é mais difícil, por serem assintomáticos ou por apresentarem sintomas não específicos. O diagnóstico precoce do processo inflamatório ou infeccioso permite tratamento rápido e também o impedimento de outras complicações. Além disto, a distinção entre inflamação e infecção é de extrema importância, bem como a provável localização. O uso de leucócitos radiomarcados, já estudados e aplicados em várias patologias, é o método de escolha para visualização de focos de infecção e inflamação. A cintilografia de leucócitos radiomarcados foi introduzida em 1976 por McAffe e Thakur e desde então é usada para diagnosticar diferentes patologias que envolvem infiltração leucocitária como distúrbios inflamatórios do intestino, infecção óssea ou prótese-vasculares entre outras. A marcação dos leucócitos in vitro pode ser realizada com ${ }^{111}$ In utilizando-se oxima ou tropolona como ligante ou com ${ }^{99 \mathrm{~m}} \mathrm{Tc}$, tendo a hexametilpropileno amino oxima (HMPAO) como ligante, resultando em um complexo lipofilico. A melhor disponibilidade, menor tempo de realização do exame, melhor propriedade física e menor dose de radiação para o paciente, resultou na preferência pelo agente HMPAO marcado com ${ }^{99 m} \mathrm{Tc}$, ao invés do ${ }^{111} \mathrm{In}$, para a maioria das indicações na maioria dos paises. Entretanto, a marcação empregando o agente HMPAO 
apresenta como desvantagens a curta estabilidade do reagente marcado, as exigências relacionadas ao processo de marcação (tempo pós-eluição do ${ }^{99 m} \mathrm{Tc}$ ), além do custo elevado, pois se trata de produto importado. Este trabalho visou o desenvolvimento do reagente liofilizado de glucoheptonatoestanho para marcação de leucócitos com ${ }^{99 \mathrm{~m} T \mathrm{~T}}$ in vitro pelo método de préestanização. A otimização da técnica de marcação foi realizada através da incubação dos leucócitos, isolados de sangue total, com diferentes volumes do reagente de glucoheptonato-estanho por diferentes tempos à $37^{\circ} \mathrm{C}$ (préestanização), com posterior marcação com ${ }^{99 \mathrm{~m}} \mathrm{Tc}(185 \mathrm{MBq})$, incubados à temperatura ambiente por 20 minutos. O rendimento da marcação foi superior a $90 \%$ na condição ótima de marcação. O reagente liofilizado mostrou-se estável por mais de 90 dias. As imagens cintilográficas obtidas 1 , 2 e 3 horas após a administração dos leucócitos radiomarcados em coelho New Zeland demonstraram a alta eficiência de marcação de processo inflamatório provocado a partir da administração local de terebentina. O método de marcação de leucócitos desenvolvido apresenta aplicação promissora na clínica médica, com proposta de redução de custo do procedimento, apesar de ser um procedimento mais demorado quando comparado ao procedimento que utiliza o quelante lipofílico de HMPAO. 


\section{ABSTRACT}

\section{DEVELOPMENT OF LYOPHILIZED KIT OF TIN-GLUCOHEPTONATE FOR IN VITRO LABELING OF LEUCOCYTES WITH ${ }^{99 \mathrm{~m}}$ TC \\ Rosemeire Fagundes Nascimento}

The study and localization of inflammatory and infection process in Nuclear Medicine represents a relevant tool in diagnostic procedures. In same cases, the diagnostic is easy and based on anamneses and clinical observation; in other cases, the patients are assimptomatic or present non specific symptoms that difficult the diagnostic. The early diagnostic of inflammatory or infectious process allow the early introduction of therapy and prevents complications. Farther, the differentiation between inflammation and infection is of extreme importance as well as the localization of the focus. The use of labeled leucocytes, studied and applied in much pathologies, is the method of choice for the visualization of inflammation and infection. The scintigraphy using labeled leucocytes was introduced at 1976 by McAffe and Thakur and since of this is used in the diagnostic of different pathologies related to leucocyte infiltration like intestinal inflammatory disease, bone or prosthetic-vascular infections. The in vitro labeling of leucocytes with ${ }^{111}$ In was performed using oxime or tropolone as ligand and with ${ }^{99 \mathrm{~m}} \mathrm{Tc}$ using hexametylpropylene amine oxime (HMPAO) as ligand, resulting in a lipophilic complex. The ${ }^{99 m}$ Tc-HMPAO complex was preferably employed in many indications and countries do to the ideal physical properties of ${ }^{99 \mathrm{~m}} \mathrm{Tc}$ that results in low dose to the patient. However, the labeling employing the HMPAO complex results in some disadvantages like the low stability of the complex, and some requirements related to the ${ }^{99 \mathrm{~m}} \mathrm{Tc}$ elution (like the time pos elution), beyond the high cost of the compound that is imported. The aim of this work was the development of a tin-glucoheptonate lyophilized kit for in 
vitro leucocytes labeling with ${ }^{99 m} \mathrm{Tc}$ using the pre stannization method. The optimization of the labeling technique was developed using leucocytes isolated from total blood and employing different volumes of the tinglucoheptonate reagent and different incubation times at $37^{\circ} \mathrm{C}$ (prestannization), and posterior labeling with ${ }^{99 \mathrm{~m}} \mathrm{Tc}(185 \mathrm{MBq})$, after 20 minutes reaction at room temperature. The labeling yield was superior to $90 \%$ using the optimized labeling conditions. Lyophilized reagent was stable after 90 days. Scintilographic images obtained 1, 2 e 3 hours after the administration of labeled leucocytes in New Zeland rabit, showed good uptake on inflammatory focus promoted by tupertine injection. The leucocytes labeling method developed can be probably applied in clinical procedures and represents cost effective method in substitution of the lypophilic complex of HMPAO. 


\section{INTRODUÇÃO}

\section{O papel da Medicina Nuclear na infecção e inflamação}

A Medicina Nuclear é uma especialidade médica que emprega radiofármacos com finalidade diagnóstica e terapêutica. Habitualmente os materiais radiativos são administrados in vivo e apresentam distribuição em determinados órgãos ou tipos celulares. Esta distribuição pode ser ditada por características do próprio elemento radioativo, como no caso das formas radioativas do iodo que, a semelhança do iodo não radioativo, é captado pela tiróide que o emprega na sintese hormonal.

Outras vezes, o elemento radioativo é ligado a um outro grupo químico, formando um radiofármaco com afinidade por determinado tecido, como no caso dos compostos a base de fosfato ligado ao tecnécio-99m que são captados pelos ossos.

A Medicina Nuclear fornece informações de processos patológicos como de processos bioquímicos. Por meio de obtenção de imagens cintilográficas, difere de outros métodos de diagnósticos de imagem convencionais como raio- $X,(R X)$, tomografia computadorizada (TC) e ressonância magnética nuclear (RMN), os quais fornecem, com alta resolução, alterações morfológicas que ocorrem em distúrbios específicos. ${ }^{2,3}$

Além disto, as técnicas da Medicina Nuclear permitem imagens do corpo inteiro, enquanto TC e RMN focam somente em uma parte do corpo. No caso de diagnósticos de processos inflamatórios e infecciosos, os processos podem ser localizados por TC ou RMN, enquanto a Medicina Nuclear pode confirmar como inflamatórios e infecciosos, através de leucócitos radiomarcados os quais migram para a área da lesão. 
A deteç̧ão cintilográfica da infecção e inflamação permite determinar não apenas a localização, como também o número de focos em todo o organismo. Como as imagens são baseadas em alterações fisiológicas e bioquímicas dos tecidos, os focos de infecção e inflamação podem ser visualizados em fases precoces quando alterações anatômicas ainda não são notadas pelos outros métodos de diagnósticos por imagem. ${ }^{3}$

Recentemente, novos radiofármacos marcados com tecnécio$99 \mathrm{~m}$ como as citocinas (interleucinas IL-2, IL 6 e IL 8), imunoglobulinas policlonais humanas e anticorpos monoclonais antigranulócitos foram desenvolvidos para melhorar a especificidade dos agentes para diagnósticos da inflamação e infecção.

Entretanto, a disponibilidade destes novos agentes é limitada e a cintilografia de leucócitos radiomarcados ainda é considerado o melhor método disponivel em Medicina Nuclear para imagem de infecção e inflamação.

Até o momento não existe nenhum radiofármaco que possua todas as características desejáveis de um agente para visualização de processo inflamatório e infecção.

No Brasil, os compostos comumente utilizados em detecção de focos de infecção e inflamação são o citrato de gálio $\left({ }^{67} \mathrm{Ga}\right)$ e os leucócitos marcados, devido à disponibilidade comercial desses radiofármacos. A marcação de leucócitos empregando complexo lipofilico HMPAO- ${ }^{99 m} \mathrm{Tc}$ (hexametilpropilenoamina oxima), considerado o melhor agente para detecção de inflamação e infecção, além de constituir-se em uma técnica trabalhosa, é de custo elevado por se tratar de um produto importado. ${ }^{1,24}$ 


\section{OBJETIVO}

O objetivo deste trabalho foi desenvolver um reagente liofilizado de glucoheptonato-estanho para marcação de leucócitos com tecnécio-99m in vitro, tendo em vista a aplicabilidade da técnica na detecção de processos de infecção e inflamação.

Sendo que para tal foram estabelecidas as melhores condições de marcação dos leucócitos com o reagente de glucoheptonato-estanho para obter rendimento de marcação próximo ou superior ao obtido com HMPAO, reduzindo assim o custo envolvido nesta técnica diagnóstica. ${ }^{7,8}$ 


\section{REVISÃO BIBLIOGRÁFICA}

Estudos para demonstrar lesões inflamatórias começaram por volta de 1959 quando Athens e colaboradores marcaram leucócitos com diisopropilfluoro fosfato marcado com fósforo-32. ${ }^{38}$

Winkelman e colaboradores marcaram leucócitos com cromo-51 in vitro e foram bem sucedidos mostrando abscessos peritoneais em coelhos. $^{39}$

O radiofármaco citrato de gálio- 67 foi inicialmente proposto para delineação de tumores e, mais tarde, demonstrado acumular em lesões inflamatórias, sendo largamente utilizado e aceito como padrão em estudos de novos agentes para visualização de focos de inflamação e infecção.

Em 1977 Thakur e colaboradores estudaram a marcação de leucócitos com indio-111 ( ${ }^{111}$ In) e as células marcadas foram aplicadas para o diagnóstico clinico e evolução de uma variedade de patologias.

Posteriormente, técnicas mais refinadas foram desenvolvidas, como a marcação específica de leucócitos in vivo por anticorpos como os anticorpos antigranulócitos, que já estão sendo utilizados na rotina clínica. A marcação de outras proteinas e peptídeos estão sendo investigadas para possivel aplicação para imagem cintilográfica de inflamação. ${ }^{50}$ 


\subsection{PROCESSO INFLAMATÓRIO}

\section{Fisiologia dos leucócitos}

Os leucócitos são os principais componentes da resposta inflamatória e imune. Eles protegem contra infecções e neoplasias e ainda dão assistência na limpeza do tecido danificado. Os precursores nucleares das células se diferenciam em células maduras dentro da medula óssea.

A contagem de leucócitos para um individuo adulto normal é de 4,5 a $11,0 \times 10^{3}$ leucócitos $/ \mathrm{mm}^{3}$, sendo a série granulocítica 55 a $65 \%$, linfócitos 25 a $35 \%$ e monócitos 3 a $7 \%$.

Os leucócitos passam pequena parte ( 6 a 7 horas ) de sua vida curta no sangue periférico, principalmente na função de transporte para os locais onde há necessidade. Em resposta a um estimulo inflamatório, os neutrófilos migram para a área lesada que os atraem (quimiotaxia) e entram nos tecidos "rastejando" (diapedese) entre as células endoteliais póscapilares. Eles aumentam sua adesividade, agregam-se e aderem à superfície endotelial, fagocitam o agente causador da lesão ou corpo estranho e, por meio de enzimas, destroem-no dentro dos seus vacúolos citoplasmáticos.

Os eosinófilos mediam as reações alérgicas e ajudam a proteger contra infestações parasitárias. Os linfócitos desempenham um papel importante nas reações imunes. Embora sua função não imunológica na inflamação na fase aguda seja pouco conhecida, eles chegam aos sítios de inflamação em maior número na fase crônica da resposta inflamatória.

Os monócitos atuam como limpadores dos tecidos, fagocitando células danificadas ou bactérias e retirando substâncias químicas e toxinas. 
Nos sítios da inflamação eles se transformam em macrófagos de tecidos, além da função imunológica. ${ }^{6}$

\section{Fisiopatologia da infecção e da inflamação}

A Inflamação é a resposta tecidual ao dano provocado. Esta induz a chegada de células do sistema imunológico (leucócitos), de proteinas séricas especializadas e de mediadores químicos ao local da lesão. A infecção implica em resposta inflamatória, porém provocada por microorganismos (fungos, bactéria, vírus).

A reação inflamatória é desencadeada por produtos gerados a partir do dano tecidual. Este pode ocorrer por infecção, trauma tecidual, partículas estranhas, isquemia e neoplasias. A infecção pode estar presente sem inflamação associada, como acontece nos pacientes imunodeprimidos.

Os sinais clássicos da inflamação são: hiperemia, edema, calor, rubor e dor.

A resposta inflamatória resulta em um aumento do fluxo sangüineo regional, aumento da permeabilidade das vênulas na região afetada e migração de leucócitos para fora dos vasos sangüíneos em direção aos tecidos (quimiotaxia).

O plasma carrega leucócitos para o local da inflamação e também uma série de proteínas, tais como opsoninas, fatores de complementos, anticorpos, bem como mediadores quimicos como histamina, serotonina e bradicinina, que modulam a resposta inflamatória. ${ }^{5,6}$ 


\subsection{Radiofármacos utilizados em imagem de infecção e inflamação}

Inúmeros agentes radiomarcados estão disponíveis para visualização de inflamação e infecção. Todos eles com vantagens e desvantagens, de forma que não existe um radiofármaco ideal, ou seja, com acúmulo rápido no órgão de interesse, mas não em tecidos normais, com baixa toxicidade, rápido clareamento sangüíneo, excreção preferencialmente renal, proporcionando imagem nítida e facilitando o parecer do médico nuclear. Deve ser de fácil e rápida preparação, boa disponibilidade, baixo custo, além de ser seletivo na diferenciação entre infecção e inflamação não microbiana. Além de preparo rápido e simples deve ser confiável e marcado com radionuclídeo adequado para diagnóstico de imagem., ${ }^{3,5,19,21}$

\section{Tecnécio-99m : o radionuclídeo ideal}

A maioria dos procedimentos de diagnósticos em Medicina Nuclear utiliza radiofármacos marcados com tecnécio-99m.

O tecnécio, o elemento 43 da tabela periódica, é um metal de transição na posição logo abaixo do elemento manganês. É um elemento atípico, não sendo encontrado na natureza e nenhum dos seus isótopos é estável. Foi descoberto e produzido pela primeira vez em 1937 e o seu nome é de origem grega que significa artificial sendo o primeiro elemento artificial produzido pelo homem. O tecnécio-99m é obtido pelo decaimento radioativo do molibdênio-99.

É obtido de gerador ${ }^{99} \mathrm{Mo}-{ }^{99 m}$ Tc na forma de pertecnetato de sódio. $O$ pertecnetato possui um átomo de tecnécio para quatro átomos de oxigênio, assim o seu estado de oxidação é +7 . O tecnécio na forma de 
pertecnetato é quimicamente muito estável de maneira que não reage prontamente ou marca outros compostos.

Como conseqüência, a primeira etapa na preparação de radiofármacos marcados com tecnécio-99m, é usar o cloreto estanoso $\left(\mathrm{SnCl}_{2}\right)$ como agente redutor para promover a redução do estado de valência do tecnécio +7 a estado de oxidação menor $(+3,+4$ ou +5$)$. Com número de oxidação menor, 0 átomo de tecnécio pode se complexar com moléculas para formar radiofármacos marcados com tecnécio-99m.

O tecnécio $-99 \mathrm{~m}$ é considerado o melhor radionuclídeo para procedimentos diagnósticos em Medicina Nuclear pelas ótimas caracteristicas físicas que possui, ou seja, tempo de meia-vida de 6,02 horas, fóton gama com energia de $140 \mathrm{keV}$ e boa disponibilidade comercial uma vez que é obtido de gerador. ${ }^{9,10}$

Muitos radiofármacos já desenvolvidos para demonstração cintilográfica de inflamação e infecção já são de uso clínico rotineiro. Estes podem ser classificados em duas grandes categorias de acordo a especificidade, ou seja, radiofármacos específicos e os radiofármacos inespecíficos. ${ }^{3}$

Entre os radiofármacos especificos estão os leucócitos radiomarcados, receptores específicos de pequenas proteínas e peptídeos e anticorpos monoclonais radiomarcados. Já os radiofármacos inespecíficos incluem os colóides radiomarcados, lipossomas, as macromoléculas tipo imunoglobulinas, dextran e albumina humana. ${ }^{5}$ 


\subsubsection{Radiofármacos inespecíficos para visualização de inflamação e infecção}

O aumento do fluxo sanguíneo, permeabilidade vascular e transudação são processos que podem ser utilizados para o acúmulo não específico dos traçadores. Deve-se enfatizar que todos os radiofármacos acumulam-se no foco de inflamação e infecção, pelo menos em parte, devido a processos não específicos. Exemplos de traçadores não especificos que se acumulam no sítio da inflamação e infecção baseado no aumento da permeabilidade vascular são: ${ }^{3,5,21,26}$

\section{a) Citrato de $\mathrm{Ga}^{67}$}

Pode ser utilizado para diferentes situações patológicas, principalmente infecção. Quando administrado na circulação, o citrato de ${ }^{67} \mathrm{Ga}$ liga-se à transferrina circulante e este complexo chega até o foco de infecção/ inflamação devido ao aumento da permeabilidade vascular.

De maneira geral a transferrina leva ${ }^{67} \mathrm{Ga}$ até o abscesso. Uma vez no abscesso $0^{67} \mathrm{Ga}$ pode ser transferido da transferrina para a lactoferrina (LF), ferritina ou proteínas sideróforas . A lactoferrina apresenta afinidade alta pelo ${ }^{67} \mathrm{Ga}$ e pode removê-lo da transferrina. Esta proteína está presente nos grânulos secundários dos leucócitos polimorfonucleares (granulócitos) e é expulsa do grânulo quando há ataque bacteriano.

A lactoferrina presente no foco pode se ligar a receptores presentes nos monócitos ou macrófagos e levar $0^{67} \mathrm{Ga}$ até a ferritina intracelular. Os microorganismos patogênicos presentes num abscesso purulento, são provavelmente, o fator mais importante para o acúmulo do ${ }^{67} \mathrm{Ga}$, pois a bactéria pode capturar uma quantidade significativa de ${ }^{67} \mathrm{Ga}$. 
Ocorre captação fisiológica do citrato de ${ }^{67} \mathrm{Ga}$ no fígado, ossos, medula óssea e intestino. É excretado parcialmente pelos rins (nas primeiras 24 horas após a injeção) e também via trato gastrintestinal.

A cintilografia com o citrato de ${ }^{67} \mathrm{Ga}$ tem grande sensibilidade tanto para infecção aguda como crônica e inflamação. Entretanto, existem algumas limitações para a sua aplicação clínica. A especificidade deste traçador é baixa devido à excreção via trato-gastrintestinal e também pelo acúmulo em tecidos tumorais. As melhores imagens diagnósticas só são obtidas após 72 horas da sua administração. Tais características desfavoráveis limitam sua aplicação clínica. ${ }^{36}$

\section{b) Imunoglobulinas}

Inicialmente havia a hipótese de que a imunoglobulina humana policlonal era retida no foco inflamatório devido a interação com receptores expressos pelos leucócitos.

Mais tarde, estudos demonstraram que a imunoglobulina humana policlonal radiomarcada acumula-se no foco infeccioso e inflamatório através de extravasamento não específico devido ao aumento da permeabilidade vascular no local.

A imunoglobulina policlonal humana pode ser marcada $\mathrm{com}^{111}$ In ou com ${ }^{99 m} \mathrm{Tc}$. Ambos agentes apresentam clareamento sanguíneo lento e captação no fígado, baço e rins. Os ensaios clínicos destes agentes demonstraram a excelente capacidade de localização de infecção e inflamação músculo-esquelética e também bons resultados para infecção pulmonar, principalmente em pacientes imunodeprimidos, e inflamação abdominal. A pequena sensibilidade para diagnóstico de endocardite e lesões vasculares em geral deve-se ao alto nível de atividade circulante por longo tempo. A limitação geral da imunoglobulina humana policlonal 
radiomarcada é o longo tempo entre a injeção e a aquisição da imagem (24 a 48 horas).

\section{c) Lipossomas}

São esferas de uma ou duas camadas lipídicas envolvendo um conteúdo aquoso. Os lipossomas foram propostos como veículo para imagem de infecção há mais de 20 anos, porém estes agentes são tidos pelo sistema imunológico como antígenos, estimulando o sistema mononuclear-fagocitico, o qual rapidamente os retira da corrente sangüínea.

No entanto, se a superfície do lipossoma for recoberta com um polimero hidrofilico como o polietilenoglicol (PEG), isto impede a ação do sistema mononuclear-fagocitico, prolongando-se a permanência dos lipossomas na circulação e aumentado-se assim a sua captação em focos infecciosos devido ao aumento da permeabilidade no local. A marcação é rápida (poucos minutos) e as primeiras avaliações clínicas mostraram boas imagens de focos de infecção ${ }^{32}$

\section{d) Sistema avidina-biotina}

Avidinas são uma família de proteinas e a estreptavidina é uma das proteinas desta família. A biotina é um composto de baixo peso molecular que pode ser radiomarcado. A avidina e estreptavidina ligam-se à biotina com extrema afinidade.

O uso do sistema avidina-biotina está baseado no fato da avidina (ou estreptavidina) localizar-se de forma não específica em focos de infecção devido ao aumento da permeabilidade vascular no local. 
Primeiramente injeta-se a avidina (ou estreptavidina) e a biotina radiomarcada é injetada horas depois. Diagnósticos com boa precisão foram obtidos em estudos de infecção vascular e osteomielite crônica. ${ }^{33}$

\subsubsection{Radiofármacos específicos para visualização de inflamação e infecção}

O processo específico de acúmulo do radiofármaco no local da lesão compreende um número de possiveis interações entre o radiofármaco e o órgão ou tecido alvo, como por exemplo, ligação a receptores e ligação do tipo antígeno-anticorpo. A especificidade implica na capacidade do radiofármaco seletivamente distinguir focos de inflamação de outros eventos patológicos como também de tecidos normais. ${ }^{5}$

A especificidade pode estar ligada a diferentes mecanismos. Entre os radiofármacos específicos citam-se :

a) Leucócitos marcados in vitro ou in vivo.

Os leucócitos atingem o local ou foco da inflamação/infecção por quimiotaxia e podem, portanto, ser usados para transportar radionuclídeo para a área inflamada proporcionando assim a localização de focos inflamatórios. Eles se movem para o foco e se concentram no local em grande número. 


\section{a.1 Leucócitos marcados in vivo}

Este método tem por objetivo marcar os leucócitos in vivo (na circulação sangüínea ou no foco). O procedimento de marcação é fácil e não requer a manipulação de sangue potencialmente contaminado.

$O$ uso de anticorpos monoclonais radiomarcados contra antígenos presentes na superfície dos granulócitos foi um dos primeiros estudos realizados visando a marcação de leucócitos in vivo. ${ }^{28}$

Alguns anticorpos anti-granulócitos foram avaliados para imagem de infecção, tais como, anti-NCA-95 lgG, anti-NCA-90 Fab'e anti-SSEA-1 lgM. Cada um desses anticorpos anti-granulócitos marcados com ${ }^{99 \mathrm{~m}} \mathrm{Tc}$ ou ${ }^{123}$, permite um preciso delineamento da infecção.

Como estes agentes radiomarcados são compostos diferentes dos leucócitos radiomarcados in vitro, apresentam biodistribuição diferente. De modo geral, o clareamento sangüineo das preparações com IgG é muito lento, gerando uma alta radiatividade de fundo que decresce lentamente com o tempo. Por esta razão, o tempo entre a injeção do anticorpo radiomarcado e a aquisição da imagem é relativamente longa. Não há captação inicial nos pulmões e a captação no baço é muito menor em comparação com os leucócitos marcados in vitro.

Os radiofármacos baseados em anticorpos anti-granulócitos permitem a visualização de focos de infecção com uma sensibilidade entre 80 e $90 \%$.

Devido ao clareamento sangüíneo lento, é necessário que as imagens sejam realizadas 24 horas após a administração do radiofármaco para uma correta localização dos focos inflamatórios. A maior desvantagem dos anticorpos monoclonais murínicos é que eles podem induzir a produção de anticorpos anti-murínicos, os quais podem resultar em biodistribuição alterada com injeções subseqüentes. ${ }^{17}$ 


\section{a.2 Leucócitos marcados in vitro}

A marcação de leucócitos in vitro foi desenvolvida entre as décadas de setenta e oitenta e até hoje ainda é considerada como padrão ouro na Medicina Nuclear para imagem de infecção e inflamação.

Após administração intravenosa, os leucócitos marcados são seqüestrados pelos pulmões com subseqüente clareamento rápido da atividade. Há um clareamento sangüíneo rápido e, em muitos casos, há uma captação alta em infiltrados granulocíticos, enquanto uma substancial porção acumula-se no baço. Portanto, como radiofármaco, os leucócitos marcados são indicadores específicos da infiltração leucocitária no foco, mas não específicos para infecção.

McAfee e Thakur desenvolveram uma técnica de marcação de leucócitos in vitro com ${ }^{111}$ In usando oxinato como quelante. ${ }^{42}$

Peters e colaboradores desenvolveram uma técnica de marcação usando HMPAO, um quelante lipofilico, que permite marcação eficiente dos leucócitos com ${ }^{99 \mathrm{~m}} \mathrm{Tc}^{43}$

Devido às características radioativas ótimas do ${ }^{99 \mathrm{~m}} \mathrm{Tc}$, os leucócitos marcados com este radionuclídeo substituíram os marcados com ${ }^{111} \mathrm{ln}$ em muitas indicações.

O excelente desempenho dos leucócitos radiomarcados para imagem de infecção e inflamação foi demonstrada em uma série de estudos onde observou-se que a sensibilidade pelo foco excedeu $95 \% .{ }^{43,44}$ Havia uma preocupação em relação a possibilidade dos leucócitos marcados não serem capazes de detectar infecção crônica, pois essas infecções geram resposta leucocitária bem menos intensa que as agudas. No entanto, um estudo com 155 pacientes mostrou que a sensibilidade dos leucócitos marcados para 
detecção de infecções agudas (90\%) não foi significativamente diferente da sensibilidade de detecção de infecções crônicas. ${ }^{44}$

Em relação à precisão do diagnóstico não há um agente para imagem de inflamação melhor que leucócitos marcados. Porém estes agentes apresentam como desvantagens a necessidade da coleta de volume significativo de sangue, que por sua vez é potencialmente contaminado, além de preparação longa. ${ }^{11,12,18}$

- Leucócitos marcados por método de complexo lipofílico: diversos complexos lipofilicos de ${ }^{99 m} \mathrm{Tc}$ foram propostos para marcação de células sangüíneas, mais especificamente leucócitos e plaquetas. Dentre eles, o HMPAO- ${ }^{99 m} \mathrm{Tc}$ tem mostrado resultados superiores. ${ }^{99 \mathrm{~m}} \mathrm{Tc}$ forma com o HMPAO um complexo lipofílico, capaz de penetrar a membrana das células por difusão passiva. Uma vez dentro da célula, o complexo é convertido em um complexo hidrofílico, aparentemente devido à alteração de $\mathrm{pH}$, e este complexo hidrofilico é retido no interior da célula. ${ }^{11}$

- Leucócitos marcados por método de pré-estanização: o pertecnetato, $\left({ }^{99 \mathrm{~m}} \mathrm{TcO}_{4}^{-}\right)$forma na qual o ${ }^{99 \mathrm{~m}} \mathrm{Tc}$ é eluido dos geradores de ${ }^{99} \mathrm{Mo}-{ }^{99} \mathrm{Tc}$ de coluna cromatográfica, não é capaz de ligar-se efetivamente às células, com estabilidade suficiente que permita a realização dos exames clinicos. O tecnécio assume, na forma de pertecnetato, o estado de oxidação $+7 \mathrm{e}$, nesta forma, entra e sai da célula, sem fixar-se. Para incorporar-se à célula sangüínea, o $\mathrm{Tc}(\mathrm{VII})$ deve ser reduzido a estados de oxidação inferiores e esta redução pode ser feita utilizando-se como agente redutor o $\mathrm{SnCl}_{2}$ ( cloreto estanoso), daí o nome de mecanismo de pré -estanização. ${ }^{4,7,8}$

$\mathrm{Na}$ marcação de leucócitos por mecanismo de pré-estanização, utilizam-se reagentes liofilizados contendo cloreto estanoso $\left(\mathrm{SnCl}_{2}\right)$, estabilizado na presença de um ligante específico como glucoheptonato de cálcio. 
O botão leucocitário é obtido a partir da centrifugação de amostra de sangue coletada do paciente e submetido à estanização com solução de glucoheptonato-estanho preparada a partir da dissolução do reagente liofilizado com solução salina. Após incubação para estanização das células, as mesmas são lavadas e submetidas à marcação com solução de pertecnetato de sódio para posterior reinjeção no paciente .

\section{b) Peptídeos Quimiotáticos}

Os peptideos com alta afinidade por receptores expressos preferencialmente por leucócitos podem ser usados para marcar leucócitos in vivo. Uma grande variedade de peptídeos que se ligam a receptores expressos pelas células brancas tem sido avaliada para detecção de infecção.

O primeiro peptídeo a ser estudado quanto a habilidade para detecção de focos de infecção/inflamação foi o peptídeo quimiotático formilmetionil-leucil-fenilalanina (FMLF). Este peptídeo composto por três aminoácidos com um grupo formil na porção $N$-terminal é um fator quimiotático produzido por bactérias, que se liga a receptores nos leucócitos com alta afinidade. Estudos realizados demonstraram que mesmo em baixas doses, o FMLF radiomarcado induz uma trasiente granulocitopenia.

Foi desenvolvido um agente com alta atividade específica marcado com $^{99 m}$ Tc com o objetivo de reduzir a indução da granulocitopenia. ${ }^{46}$

Vários antagonistas também foram desenvolvidos para contrapor este efeito biológico (granulocitopenia). Porém, estes antagonistas apresentam baixa captação no foco de infecção, muito provavelmente, devido a reduzida afinidade pelo receptor. ${ }^{20,22,25,27}$ 


\section{c) Citocinas}

As citocinas radiomarcadas são uma interessante classe de radiofármacos baseada em proteínas de baixo peso molecular. As interleucinas 1,2 e 8 e o fator plaquetário 4 ( IL-1, IL -2 , IL-8 e PF-4) estão entre estas citocinas.

A IL-1 liga-se a receptores expressos nos leucócitos, com alta afinidade. Porém mesmo em baixas doses, efeitos adversos como hipotensão, impedem a aplicação clínica da IL-1 radiomarcada.

A IL-2 radiomarcada liga-se especificamente a receptores IL-2 expressos nas células $T$ ativadas. A IL-2 marcada tanto com ${ }^{123} \mid$ como ${ }^{99 m}$ Tc tem sido estudada para localização de regiōes com infiltração de linfócitos.

A IL-8 liga-se a receptores nos neutrófilos com alta afinidade. 0 acúmulo de IL-8 radioiodada no abscesso é rápido e alto. A atividade especifica relativamente baixa resulta em transiente redução na contagem de leucócitos periféricos após uma dose de $\left|\mathrm{L}-8{ }^{123}\right| \mathrm{de} 25 \mu \mathrm{g} /$ $\mathrm{Kg}$, seguida de leucocitose por algumas horas.

O PF-4 liga-se a receptores expressos nos neutrófilos e monócitos e é denominado de agente neutralizante de heparina do organismo.

Este peptídeo marcado com ${ }^{99 \mathrm{~m}} \mathrm{Tc}$ tem sido estudado em pacientes para se avaliar a aplicabilidade do mesmo como agente de imagem para detecção cintilográfica de infecção e inflamação e os resultados são favoráveis. Nenhum efeito adverso sistêmico foi observado, ou seja, a transiente neutropenia. Porém, em alguns 
pacientes foi observada excessiva captação na tireóide, o que sugere a instabilidade do composto in vivo com liberação de ${ }^{99 \mathrm{~m}} \mathrm{Tc}^{2,3}$

\section{d) Antibióticos radiomarcados}

Nenhum dos agentes discutidos até aqui é capaz de diferenciar infecção de inflamação, uma vez que acumulam-se no foco devido a características comuns da infecção e inflamação. A discriminação entre infecção bacteriana e inflamação estéril é clinicamente relevante em algumas situações. O primeiro radiofármaco proposto para esta aplicação foi a ciprofloxacina marcada com ${ }^{99 \mathrm{~m}} \mathrm{Tc} .{ }^{24,27}$

A ciprofloxacina, uma fluoroquinolona, é um agente antimicrobiano que se liga às enzimas DNA-topoisomerase IV e DNA-girase presentes em várias bactérias em divisão celular. Portanto, este agente marcado com ${ }^{99 \mathrm{~m}} \mathrm{Tc}$ teoricamente é capaz de discriminar entre infecção e inflamação estéril.

Os primeiros estudos clínicos mostraram alta precisão na detecção de infecção bacteriana. Os resultados da eficácia da ciprofloxacina- ${ }^{99 \mathrm{~m}} \mathrm{Tc}$, em 90 pacientes com suspeita de infecção revelaram sensibilidade de $70 \%$ e especificidade de $93 \%$ e ainda como este agente não se acumula em medula óssea, poderia ser útil para avaliação de infecção em próteses ortopédicas.

Em outro estudo realizado com a ciprofloxacina- ${ }^{99 m} \mathrm{Tc}$ utilizando-se um modelo animal com prótese articular infectada, previamente validado, foi verificado, assim como nos estudos clínicos, que a ciprofloxacina- ${ }^{99 \mathrm{~m}} \mathrm{Tc}$ apresentou boa sensibilidade para detecção de infecção na articulação protética, com acúmulo nos tecidos infectados próximos a prótese. No entanto, também foi observada significante captação nas articulações não infectadas, persistindo até 24 horas após 
a infecção. Tais dados são discordantes daqueles obtidos nos estudos clínicos preliminares.

\section{e) Peptídeos Antimicrobianos (HNPs)}

Os peptídeos antimicrobianos são produzidos pelos neutrófilos humanos e ficam armazenados nos grânulos dos mesmos. Geralmente contêm menos que 50 aminoácidos, carga positiva devido ao excesso de resíduos básicos como lisina e arginina e aproximadamente $50 \%$ de aminoácidos hidrofóbicos.

Apesar dos peptídeos antimicrobianos apresentarem diferentes estruturas químicas, a base de sua atividade antimicrobiana está relacionada à interação do domínio catiônico do peptídeo com a superficie do microrganismo (carga negativa). ${ }^{27}$

Além da sua atividade antimicrobiana direta, estes apresentam quimiotaxia por monócitos e linfócitos.

Os peptídeos sintéticos derivados da ubiquicidina humana são uma classe promissora de agentes cintilográficos uma vez que demonstraram diferenciar infecção de inflamação estéril em diferentes animais de laboratório. Estes traçadores detectam rapidamente infecção bacteriana assim como fúngica e ainda há uma correlação entre a quantidade de peptídeo acumulado no foco de infecção e o número de microrganismos viáveis presente. 


\section{f) Flúor- 2- desoxi-D-glicose- ${ }^{18} \mathrm{~F}$ (FDG- ${ }^{18} \mathrm{~F}$ )}

A utilização de $\mathrm{FDG}-{ }^{18} \mathrm{~F}$ tornou-se muito importante para diferenciação entre tumores malignos e benignos, determinação do estágio do tumor e avaliação da eficácia do tratamento.

Sabe-se que há aumento no metabolismo de glicose em tumores e a FDG acumula-se quantitativamente em tumores malignos in vivo basicamente devido a esse alto metabolismo nos mesmos. Entretanto, durante uma pesquisa de tumor maligno com FDG, falsos positivos ocasionalmente podem ocorrer, principalmente devido a processos infecciosos ou granulomatosos.

A utilidade da FDG- ${ }^{18} \mathrm{~F}$ para imagem de infecção foi demonstrada por vários estudos e apresenta sensibilidade e especificidade superior a $90 \%$. Especialmente bem sucedida para os casos de osteomielite, espondilite inflamatória e infecção dos tecidos moles que circundam o osso.

A resolução espacial alta e o acúmulo rápido no foco são vantagens significativas sobre a técnica convencional utilizando-se os leucócitos marcados.

Em contrapartida, o fato de a captação ocorrer em qualquer tipo de célula com metabolismo de glicose aumentado é uma limitação para o uso da $F D G-{ }^{18} \mathrm{~F}$ para imagem de infecção, uma vez que restringe sua especificidade pois não consegue distinguir entre tumor maligno e processo inflamatório. ${ }^{21}$ 


\section{MATERIAIS E MÉTODOS}

Os procedimentos de marcação de leucócitos envolvidos neste estudo foram realizados nos laboratórios de Pesquisas e Desenvolvimento do Centro de Radiofármacia do IPEN, que possui infraestrutura para manipulação de fontes radioativas abertas, com segurança para o operador e para o meio ambiente.

\subsection{MATERIAIS}

\subsubsection{Geral}

- Tubo de fundo cônico (volume total $50 \mathrm{~mL}$ )

- $\quad$ Tubo de fundo cônico (volume total $15 \mathrm{~mL}$ )

- $\quad$ Seringas descartáveis (volume total de $60 \mathrm{~mL}$ )

- Scalpes (21 G)

- $\quad$ Pipeta de Pasteur de vidro

- Frascos de vidros tipo penicilina para liofilização

- Rolhas de borracha para liofilização

- Vidraria volumétrica em geral (becker, proveta, pipeta etc...)

- Ponteiras plásticas para pipetas automáticas

- Lâmina para microscópio e lamínulas de vidro

- Câmara de Newbauer

- Suporte universal de metal

\subsubsection{Equipamentos}

- Liofilizador- Edwards, modelo supermodulyo-Inglaterra .

- Centrifuga- Hitachi - Japão 
Balança analítica - Denver - Estados Unidos

Microscópio óptico - Motic- Canadá

Agitador magnético -Nova Ética -Brasil

Calibrador de dose - Capintec, Inc -Estados Unidos

Gama câmara - Siemens- modelo LEM -Estados Unidos

Banho Maria- Fanem-Brasil

\subsubsection{Reagentes e Soluçōes}

- Solução anticoagulante-ACD (ácido cítrico anidro, citrato de sódio e glicose) - Divisão de Farmácia-Hospital das Clínicas da Faculdade de Medicina da Universidade de São Paulo (HCFMUSP)

- Soluçāo fisiológica ( $\mathrm{NaCl}$ 0,9\%)

- Água para injetáveis, estéril e apirogênica

- Solução de $\mathrm{NaCl} 1,8 \%$

- Cloreto estanoso $\left(\mathrm{SnCl}_{2} 2 \mathrm{H}_{2} \mathrm{O}\right)$ p.a- Gibco

- Glucoheptonato de cálcio p.a. - Sigma

- $\mathrm{NaOH}$ p.a-Reagen

- Ácido clorídrico concentrado p.a. - Merck

- Terebentina - . Acrilex

- Solução de Pertecnetato de Sódio $\left(\mathrm{Na}^{+} \mathrm{TCO}_{4}^{-}\right)$eluida de gerador de ${ }^{99}$ Mo- ${ }^{99 m}$ Tc-IPEN-TEC-IPEN

- Solução de Azul Triplan 0,4\% - Sigma

- Plasmasteril囚 450/0,7 6\% (amido hidroxietílico e cloreto de sódio)

- Nitrogênio gasoso - White Martins

\subsubsection{Animais}

Foi utilizado coelho adulto New Zeland, branco, com peso de aproximadamente $3,5 \mathrm{Kg}$, clinicamente selecionado como normal, 
do laboratório de experimentação animal do Centro de Medicina Nuclear da Faculdade Medicina da Universidade de São Paulo.

Todo o estudo foi realizado de acordo com as normas da COBEA (Colégio Brasileiro de Experimentação Animal

\subsubsection{Concentrado leucocitário}

\subsection{MÉTODOS}

\subsubsection{Preparo do reagente liofilizado de glucoheptonato-estanho}

Os reagentes liofilizados de glucoheptonato-estanho foram preparados em lotes de 100 frascos, de forma que cada frasco contém $100 \mathrm{mg}$ de glucoheptonato de cálcio e $263 \mu \mathrm{g}$ de $\mathrm{SnCl}_{2} \cdot 2 \mathrm{H}_{2} \mathrm{O}$.

A preparação consistiu na dissolução de $10 \mathrm{~g}$ do sal de glucoheptonato de cálcio em água previamente nitrogenada. Porém, como tal dissolução só ocorre em pH ácido, houve a necessidade da adição de ácido clorídrico concentrado até a solução atingir pH 2,0. Posteriormente, foi realizada a preparação da solução de cloreto estanoso que consistiu da dissolução de $263 \mathrm{mg}$ de $\mathrm{SnCl}_{2} \cdot 2 \mathrm{H}_{2} \mathrm{O}$ em $0,5 \mathrm{~mL}$ de ácido clorídrico concentrado e o volume final completado para $10 \mathrm{~mL}$ com água nitrogenada. Foi retirado $1 \mathrm{~mL}$ dessa solução e adicionado à solução de glucoheptonato. $\mathrm{O}$ pH da mistura foi ajustado com a solução de $\mathrm{NaOH}$ para 5,0-5,5. Cada 1 
$\mathrm{mL}$ desta solução contém a massa especificada acima. Aliquotas de $1 \mathrm{~mL}$ desta solução foram transferidas para frascos do tipo penicilina que foram posteriormente submetidos a processo de liofilização (tempo de congelamento de 4 horas e tempo de aquecimento, gradativo, de 20 horas). Os frascos liofilizados de gluco-estanho foram armazenados sob refrigeração para utilização posterior e estudo de estabilidade. Para marcação dos leucócitos, um frasco de reagente liofilizado de gluco-estanho foi reconstituído com $10 \mathrm{~mL}$ de solução fisiológica e desta solução volumes diferentes, de acordo com o estudo da variável em questão, foram utilizados para a pré-estanização do concentrado leucocitário e posterior marcação.

\subsubsection{Obtenção do concentrado leucocitário}

\section{- Coleta de sangue}

Os concentrados leucocitários utilizados nas marcações foram obtidos de amostras de sangue total de indivíduos voluntários saudáveis .

Cinqüenta mililitros de sangue venoso foram coletados com escalpe $21 \mathrm{G}$ em seringa contendo $10 \mathrm{~mL}$ do anticoagulante $A C D$ e transferidos para um tubo cônico estéril. A esse tubo foram adicionados 6,0 $\mathrm{mL}$ de Plasmasteril a $6 \%$ e aguardou-se a sedimentação expontânea das hemácias em temperatura ambiente por aproximadamente 60 minutos. Isso resultou em plasma rico em leucócitos e plaquetas mais as células vermelhas sedimentadas.

O plasma foi transferido para um tubo cônico de menor capacidade $(15 \mathrm{~mL})$, submetido a centrifugação por 5 minutos a $1000 \mathrm{rpm}$, em centrifuga não refrigerada. $O$ botão leucocitário foi isolado removendo-se 0 sobrenadante que foi descartado. 
A fim de eliminar algumas hemácias presentes no concentrado leucocitário, realizou-se a lise das mesmas adicionando-se ao concentrado de leucócitos $5 \mathrm{~mL}$ de água purificada ( água para injetáveis, estéril e apirogênica) com posterior adição imediata de $5 \mathrm{~mL}$ da solução de $\mathrm{NaCl}$ $1,8 \%$. O concentrado leucocitário foi novamente centrifugado por 5 minutos a $1000 \mathrm{rpm}$ e o sobrenadante descartado. Este procedimento foi repetido até eliminação total das hemácias.

O concentrado de leucócitos foi resuspendido com $1 \mathrm{~mL}$ de solução fisiológica ( $\mathrm{NaCl}$ 0,9\%), sendo retirada dessa suspensão uma alíquota de 50 $\mu \mathrm{L}$ e adicionada à $950 \mu \mathrm{L}$ de solução fisiológica resultando, portanto, em uma diluição 1:20 da amostra de leucócitos preparada.

Uma vez que a concentração de células foi um dos parâmetros fixados para a otimização da técnica de marcação com o reagente liofilizado de glucoheptonato-estanho, foi realizada a determinação do número de célula por mililitro, de forma que todas as marcações foram realizadas com o mesmo número de células. A determinação do número de células por mililitro, realizada através da contagem de leucócitos em Câmara de Newbauer, observada em microscópio óptico obedeceu à seguinte fórmula :

$N^{\circ}$ de células por $m L=n^{\circ}$ total de cel. contadas $x$ fator de diluição

$0,000004 \mathrm{~mL} /$ quadro $\times \mathrm{n}^{\circ}$ de quadros contados

Simultaneamente à contagem de leucócitos, realizou-se a verificação da viabilidade celular utilizando-se o teste de exclusão do Azul triplan, adicionando-se uma alíquota $(10 \mu \mathrm{l})$ da suspensão de células diluídas à uma alíquota de mesmo volume do corante Azul triplan, em uma lâmina de microscópio, homogenizando-se e incubando-se por 5 minutos, em temperatura ambiente, para posterior observação ao microscópio óptico. 
Neste procedimento as células mortas assumem coloração azulada enquanto as células vivas mantêm coloração original. ${ }^{11,12}$

\subsubsection{Estudo dos parâmetros de marcação}

O estudo das variáveis para otimização da marcação foi realizado em triplicata de amostras de concentrado de leucócitos, de forma que antes de iniciar a etapa de estanização, o concentrado de leucócitos original foi dividido em três partes iguais, em volume e número de células.

Foram estudadas as seguintes variáveis: volume do reagente de gluco-estanho (correspondente a diferentes massas de cloreto estanoso), tempo e temperatura de incubação na etapa de estanização, concentração das células, tempo e temperatura de incubação na etapa de marcação com tecnécio-99m.

\subsubsection{Estanização dos leucócitos}

Reconstituiu-se o reagente liofilizado de gluco-estanho com $10 \mathrm{~mL}$ de solução fisiológica. Como as variáveis estudadas nesta etapa foram a influência do volume do reagente liofilizado reconstituído e influência do tempo de incubação das células com o reagente liofilizado reconstituído, à triplicata do concentrado de leucócitos, foram adicionados diferentes volumes do reagente liofilizado reconstituído (diferentes massas de $\mathrm{Sn}^{+2}$ ) que foram incubadas em diferentes tempos à $37^{\circ} \mathrm{C}$. Realizou-se também a estanização à temperatura ambiente.

Após incubação, a triplicata foi centrifugada por 10 minutos a 1000rpm, desprezou-se o sobrenadante e ao precipitado de leucócitos adicionou-se $10 \mathrm{~mL}$ de solução fisiológica, e submeteu-se à nova 
centrifugação por 5 minutos a $1000 \mathrm{rpm}$ para retirada do excesso do reagente estanizante. Esta etapa de lavagem foi repetida uma vez, para obter-se o concentrado de leucócitos pronto para a radiomarcação .

\subsubsection{Radiomarcação do concentrado de leucócitos}

Após a etapa de estanização do concentrado de leucócitos, iniciouse a radiomarcação quando à triplicata de leucócitos, adicionou-se a solução de pertecnetato de sódio $\left(\mathrm{Na}{ }^{99 \mathrm{~m}} \mathrm{TCO}_{4}\right)$ eluída de gerador de ${ }^{99} \mathrm{Mo}-{ }^{99 \mathrm{~m}} \mathrm{Tc}$ (IPEN-TEC), com atividade de $185 \mathrm{MBq}(5 \mathrm{mCi})$, com incubação por 20 minutos à temperatura ambiente em local blindado para radiação. Terminada a incubação, centrifugou-se por 10 minutos a $1000 \mathrm{rpm}$ e determinou-se em seguida a eficiência de marcação.

\section{- Marcação do botão leucocitário total}

Uma vez estabelecidas as melhores condições de estanização $(4 \mathrm{~mL}$ do reagente liofilizado reconstituido, 40 minutos de incubação à $37^{\circ} \mathrm{C}$ ) e de marcação (20 minutos à temperatura ambiente), foram realizadas marcações do botão leucocitário íntegro ( $n^{0}$ de células de $1 \times 10^{7}$ a $10^{8}$ ) utilizando-se atividade de $555 \mathrm{MBq}(15 \mathrm{mCi})$ de solução de pertecnetato de sódio num volume de $300-600 \mu \mathrm{L}$. 


\subsubsection{Controle de Qualidade da Marcação}

A eficiência de marcação ( $\% E M)$ foi determinada por meio da medida da atividade do precipitado dos leucócitos em relação à atividade total utilizada, ou seja :

$E M(\%)=$ Ativ. leucócitos / (Ativ. leucócitos + Ativ. sobrenadante) $\times 100$

A viabilidade das células marcadas foi avaliada pelo teste de exclusão do Azul Triplan, conforme descrito anteriormente.

Foi realizada também rigorosa inspeção visual macroscópica durante todo o processo, observando-se a possivel variação da coloração, viscosidade ou formação de grumos.

\subsubsection{Estabilidade do reagente liofilizado}

A estabilidade do reagente liofilizado frente ao armazenamento sob condições de refrigeração foi observada mediante ensaio de marcação de leucócitos utilizando-se o procedimento padrão de marcação, para o produto liofilizado obtido até 3 meses de armazenamento.

\subsubsection{Modelo Experimental Animal}

O modelo experimental foi desenvolvido em coelho New Zeland, macho, adulto, pesando aproximadamente $3,5 \mathrm{~kg}$, do laboratório de experimentação animal do Centro de Medicina Nuclear da FMUSP. 
O foco inflamatório asséptico foi induzido pela injeção intramuscular de $0,5 \mathrm{~mL}$ de terebentina na parte interna de uma das patas, utilizando-se a outra como seu próprio controle.

Os leucócitos radiomarcados utilizados para o estudo das imagens cintilográficas no coelho, foram obtidos de sangue de voluntário humano e submetidos ao processo de marcação previamente descrito.

Após um período de 48 horas da injeção do agente de indução do foco inflamatório, administrou-se $59,2 \mathrm{MBq}(1,6 \mathrm{mCi})$ da suspensão de leucócitos-Sn ${ }^{99 \mathrm{~m}} \mathrm{Tc}$, na veia marginal da orelha do coelho. ${ }^{14,15}$

\subsubsection{Cintilografia}

As imagens cintilográficas foram obtidas 1,2 e 3 horas após a administração do radiofármaco, na projeção anterior do animal, mantido durante o exame em decúbito dorsal, por contenção adequada, sem a utilização de nenhum tipo de anestésico. A cintilografia foi realizada no Centro de Medicina Nuclear da Faculdade de Medicina da Universidade de São Paulo, em gama câmara com colimador de baixa energia para múltiplos propósitos, e utilizou-se o programa de aquisição apropriado. 


\section{5 - RESULTADOS}

\subsection{Obtenção do concentrado leucocitário}

A Tabela 1 relaciona o resultado de obtenção de botão leucocitário a partir das amostras de $50 \mathrm{~mL}$ de sangue, coletadas dos voluntários saudáveis. Os valores discriminam o número de células determinado em cada amostra, após diluição apropriada e observação microscópica em Câmara de Newbauer.

Tabela 1. Número de células leucocitárias obtidas por botão isolado nas vinte amostras de sangue coletadas

\begin{tabular}{c|c|c}
\hline $\mathbf{N}^{\circ}$ & & \\
Amostra & $\mathbf{N}^{0}$ de leucócitos/botão & Viabilidade celular \\
\hline $\mathbf{1}$ & $6,7 . \times 10^{7}$ & $>98 \%$ \\
$\mathbf{2}$ & $13,6 \times 10^{7}$ & $>98 \%$ \\
$\mathbf{3}$ & $8,4 \times 10^{7}$ & $>98 \%$ \\
$\mathbf{4}$ & $7,5 \times 10^{7}$ & $>98 \%$ \\
$\mathbf{5}$ & $7,6 \times 10^{7}$ & $>98 \%$ \\
$\mathbf{6}$ & $8,6 \times 10^{7}$ & $>98 \%$ \\
$\mathbf{7}$ & $6,7 \times 10^{7}$ & $>98 \%$ \\
$\mathbf{8}$ & $14,7 \times 10^{7}$ & $>98 \%$ \\
$\mathbf{9}$ & $13,2 \times 10^{7}$ & $>98 \%$ \\
$\mathbf{1 0}$ & $15,4 \times 10^{7}$ & $>98 \%$ \\
$\mathbf{1 1}$ & $7,7 \times 10^{7}$ & $>98 \%$ \\
$\mathbf{1 2}$ & $7,8 \times 10^{7}$ & $>98 \%$ \\
$\mathbf{1 3}$ & $16,2 \times 10^{7}$ & $>98 \%$ \\
$\mathbf{1 4}$ & $10,9 \times 10^{7}$ & $>98 \%$ \\
$\mathbf{1 5}$ & $17,7 \times 10^{7}$ & $>98 \%$ \\
$\mathbf{1 6}$ & $18,2 \times 10^{7}$ & $>98 \%$ \\
$\mathbf{1 7}$ & $6,7 \times 10^{7}$ & $>98 \%$ \\
& &
\end{tabular}




\begin{tabular}{c|c|c}
18 & $13,4 \times 10^{7}$ & $>98 \%$ \\
19 & $17,7 \times 10^{7}$ & $>98 \%$ \\
20 & $9,6 \times 10^{7}$ & $>98 \%$ \\
Média & $11,4 \times 10^{7}$ & $>98 \%$ \\
\hline
\end{tabular}

\section{2 - Otimização da técnica de marcação de leucócitos com o reagente liofilizado de glucoheptonato-estanho}

Nos resultados apresentados a seguir, foram utilizadas como medida de tendência central a média e como medida de dispersão, o desvio padrão.

As melhores condições de marcação de leucócitos empregando-se o reagente de glucoheptonato-estanho foram determinadas a partir da variação dos principais parâmetros envolvidos na marcação.

Ao avaliar-se a influência do volume do reagente liofilizado de glucoheptonato-estanho, ressuspendido em solução de $\mathrm{NaCl} 0,9 \%$, no rendimento de marcação dos leucócitos (Tabela 2), utilizou-se uma concentração de leucócitos de 2,2 a $2,6 \times 10^{7}$ células, atividade do pertecnetato de sódio $\left({ }^{99 \mathrm{~m}} \mathrm{Tc}\right)$ de $185 \mathrm{MBq}(5 \mathrm{mCi})$, temperatura de estanização de $37^{\circ} \mathrm{C}$, temperatura ambiente de incubação da etapa de radiomarcação e tempo de marcação de 20 minutos. Variou-se ainda neste estudo, conforme demonstrado na Tabela 2, o tempo de incubação na fase de pré-estanização. 
Tabela 2 - Influência do volume do reagente de glucoheptonatoestanho e de diferentes tempos de incubação no rendimento de marcação de leucócitos

\begin{tabular}{|c|c|c|c|}
\hline \multirow{2}{*}{$\begin{array}{c}\text { Volume do reagente } \\
\text { de gluco- } \\
\text { estanho/massa de } \\
\mathrm{Sn}^{+2}\end{array}$} & \multicolumn{3}{|c|}{ Rendimento de Marcação (\%) } \\
\hline & 10 minutos & 20 minutos & 40 minutos \\
\hline $1 \mathrm{~mL} / 26,3 \mu \mathrm{g}$ & $29,10 \pm 0,11$ & $30,00 \pm 0,10$ & $38,20 \pm 0,03$ \\
\hline $2 \mathrm{~mL} / 52,6 \mu \mathrm{g}$ & $32,20 \pm 0,10$ & $76,40 \pm 0,10$ & $87,80 \pm 0,03$ \\
\hline $4 \mathrm{~mL} / 105,2 \mu \mathrm{g}$ & $55,60 \pm 0,10$ & $79,20 \pm 0,06$ & $90,50 \pm 0,15$ \\
\hline
\end{tabular}

Para avaliar se a influência no rendimento de marcação era devida à massa de $\mathrm{Sn}^{+2}$ utilizada ou se havia influência também do volume final da solução, realizou-se triplicata de marcação utilizando-se 105,2 $\mu \mathrm{g}$ de $\mathrm{Sn}^{+2}$, porém num volume de $2 \mathrm{~mL}$ de glucoheptonato-estanho e um tempo de incubação de 40 minutos. Esta concentração foi obtida a partir da dissolução de um frasco do reagente liofilizado em $5 \mathrm{~mL}$ de $\mathrm{NaCl} 0,9 \%$ e utilização de $2 \mathrm{~mL}$ para a marcação. Também neste caso, o rendimento médio observado de $90,4 \pm 0,015 \%$, demonstrou que a massa de $\mathrm{Sn}^{+2}$, e não o volume de incubação, foi determinante no rendimento da marcação.

A Tabela 3 apresenta o resultado do estudo de variação do número de células leucocitárias no rendimento de marcação. Neste experimento, as demais condições de marcação foram mantidas constantes (4 mL de solução de glucoheptonato-estanho, 40 minutos de incubação na 
fase de pré-estanização, $185 \mathrm{MBq}(5 \mathrm{mCi})$ de pertecnetato de sódio $\left({ }^{99 \mathrm{~m}} \mathrm{Tc}\right)$, incubação à temperatura ambiente por 20 minutos).

Tabela 3 - Variação do rendimento de marcação em função do número de células utilizadas.

\begin{tabular}{l|l}
$\mathbf{N}^{\circ}$ células & Rendimento de marcação $(\%)$ \\
\hline
\end{tabular}

$$
2,2-2,6 \times 10^{7}
$$

$90,5 \pm 0,15$

(185 MBq)

$15,4-18,2 \times 10^{7}$

$92,7 \pm 0,26$

(555 MBq)

$1 \times 10^{7}$

Marcação inviável

$\mathrm{N}=3$

Utilizando-se a melhor condição de marcação, conforme observado na Tabela 2, ou seja, $4 \mathrm{~mL}$ da solução de glucoheptonatoestanho e 40 minutos de incubação, procedeu-se à marcação do botão leucocitário total, utilizando-se $15,4-18,2 \times 10^{7}$ células e $555 \mathrm{MBq}$ de pertecnetato de sódio $\left({ }^{99 \mathrm{~m}} \mathrm{Tc}\right)$. O resultado médio obtido de rendimento de marcação foi de $92,7 \pm 0,26 \%(N=3)$.

Ainda utilizando-se o botão leucocitário total e condições ideais de marcação, estudou-se o efeito do aquecimento (incubação a $37^{\circ} \mathrm{C}$ ) na fase de marcação. Neste estudo, obteve-se rendimento de marcação médio de $89,9 \pm 1,11 \%(\mathrm{~N}=3)$. 
5.3 Estabilidade do reagente liofilizado de glucoheptonato-estanho

A estabilidade do reagente liofilizado de glucoheptonato-estanho foi avaliada de forma indireta, procedendo-se à marcação de botão leucocitário por 3 meses consecutivos, após a produção dos mesmos. Os reagentes liofilizados foram mantidos sob refrigeração $\left(2-8^{\circ} \mathrm{C}\right)$ durante o período de armazenamento.

A Tabela 4 mostra os resultados obtidos de rendimento de marcações realizadas em diferentes meses após a preparação do reagente liofilizado.

Tabela 4 - Rendimento de marcação de leucócitos em função do tempo de armazenamento do reagente liofilizado de glucoheptonato-estanho

\begin{tabular}{l|c}
\hline Período de armazenamento & Rendimento de marcação (\%) \\
\hline Imediato & $90,50 \pm 0,15$ \\
1 mês & $90,20 \pm 0,21$ \\
2 meses & $89,70 \pm 0,31$ \\
& \\
\hline & \\
\hline $\mathrm{N}=3$ & $89,20 \pm 0,40$ \\
\hline
\end{tabular}




\subsection{Estudo de distribuição animal}

As Figuras 1 e 2 mostram, respectivamente, as imagens cintilográficas de corpo inteiro e das patas de coelho, obtidas após administração de leucócitos humanos marcados com a técnica de préestanização utilizando-se o reagente liofilizado de gluco-estanho. A imagem de corpo inteiro (Figura 1) foi obtida após 3 horas da administração e as imagens das patas (com e sem processo inflamatório) foram obtidas após 1 , 2 e 3 horas da administração (Figura 2).

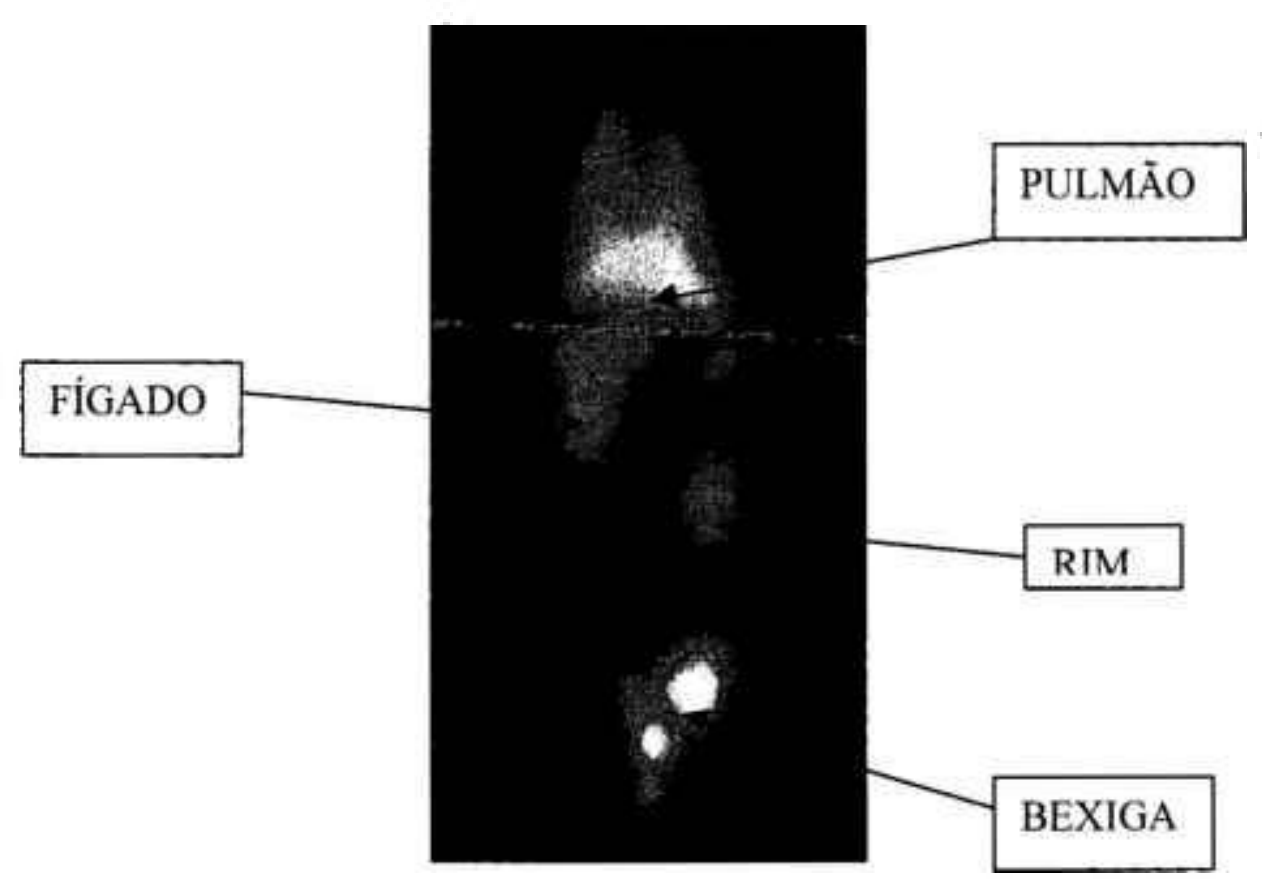

Figura 1. Cintilografia de corpo inteiro de coelho após administração de leucócitos humanos marcados com tecnécio-99m pela técnica de préestanização com glucoheptonato-estanho, adquiridas 3 horas após administração de 59,2 MBq do radiofármaco por via venosa 

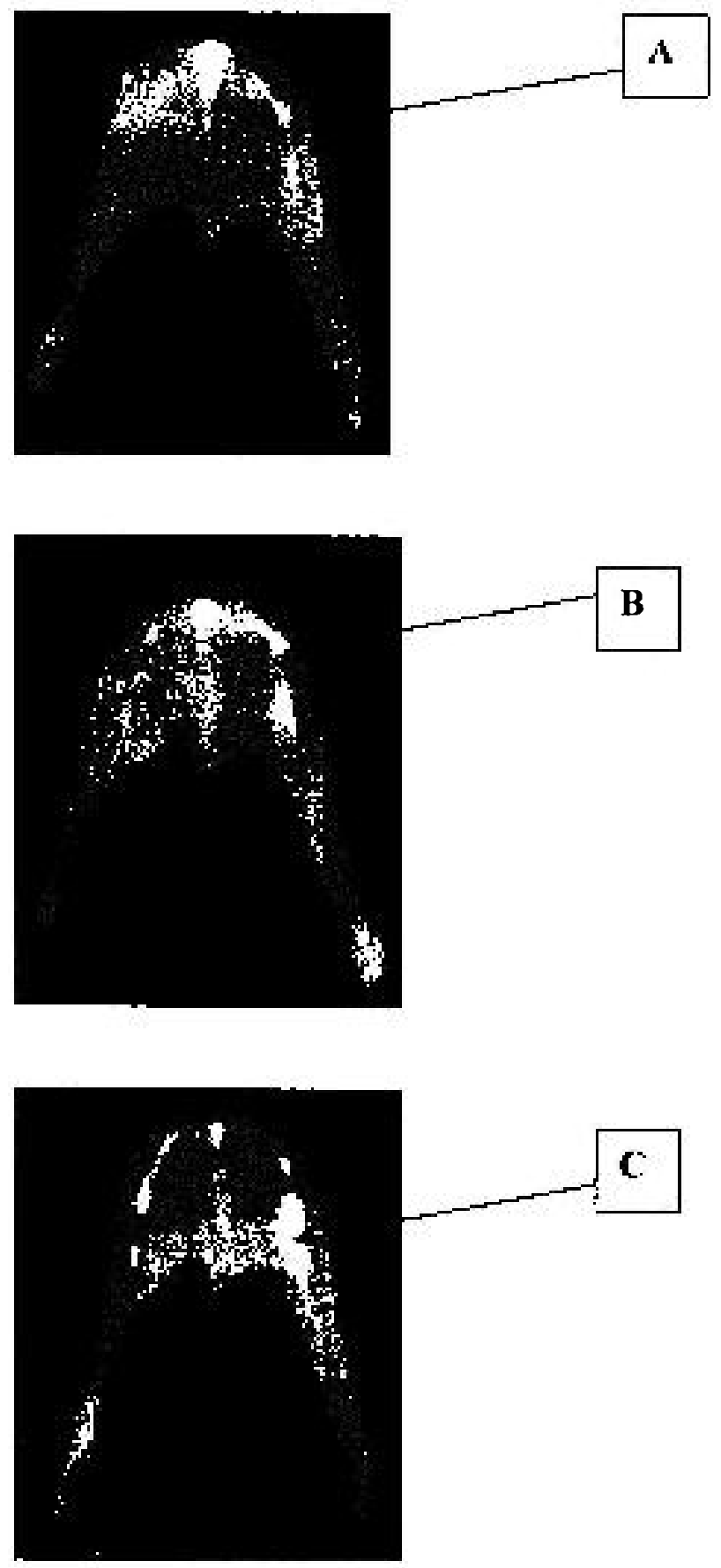

Figura 2. Cintilografias das patas de coelho com processo inflamatório à direita, provocado a partir de injeção intramuscular de terebentina, adquiridas após 1 (A), 2 (B) e 3 (C) horas da administração de leucócitos humanos marcados com tecnécio-99m pela técnica de préestanização com glucoheptonato-estanho. 


\section{DISCUSSÃO}

$O$ volume de sangue coletado por paciente $(50 \mathrm{~mL})$ mostrou-se ideal, pois o mesmo garantiu a ótima concentração de leucócitos, ou seja, acima de 6,6 $\times 10^{7}$ leucócitos (Tabela 1 ). A escolha da faixa ideal de leucócitos baseou-se no trabalho de Hammersley e colaboradores, segundo os quais é necessária a concentração mínima de 5000 leucócitos $/ \mathrm{mm}^{3}$ para obtenção de rendimentos satisfatórios de marcação, ao utilizar-se a técnica de marcação com HMPAO. ${ }^{11,18}$

O procedimento de coleta de sangue utilizando-se ACD como anticoagulante mostrou-se efetivo para processamento do mesmo e obtenção do concentrado leucocitário, não tendo sido observada formação de grumos.

A metodologia utilizada para a separação dos leucócitos é recomendada pela Sociedade Internacional de Elementos Sangüíneos Radiomarcados (ISORBE), e utilizou-se o Plasmasteril como agente acelerador da sedimentação dos eritrócitos. De acordo com a literatura, entretanto, o tempo de sedimentação recomendado para utilização deste agente de sedimentação é de 60 minutos. ${ }^{11} \mathrm{Em}$ nosso trabalho, entretanto, obtivemos melhor porcentagem de sedimentação variando-se o tempo de incubação de 1 a 2 horas, dependendo da amostra sanguinea.

Ainda com relação ao agente de sedimentação, o Plasmasteril apresenta-se como solução pronta para uso, o que constitui uma vantagem frente a outros agentes, como o Ficollpaque, que requer manipulação prévia para uso. ${ }^{31,18}$

O procedimento subseqüente de separação por centrifugação e lavagem das células com solução isotônica $(\mathrm{NaCl} 0,9 \%)$ proporcionou a obtenção de um botão leucocitário integro. Em todas as amostras os leucócitos mostraram-se viáveis, em porcentagem superior a $98 \%$ (Tabela 
1), quando observadas em microscópio óptico, comprovando a boa qualidade da técnica de separação empregada.

O estudo de otimização das condições de marcação demonstrou, a partir dos parâmetros estudados, que a massa de $\mathrm{Sn}^{+2}$ é determinante da eficiência de marcação, bem como o tempo de incubação da fase de préestanização (Tabela 2).

As condições que resultaram em melhor rendimento $(4 \mathrm{~mL}$ da solução de glucoheptonato-estanho e 40 minutos de incubação), foram extrapoladas para a marcação de botões leucocitários integros, simulando, desta forma, a marcação em condições reais de coleta e manipulação da amostra de sangue na rotina clínica da Medicina Nuclear. Os resultados obtidos na marcação do botão leucocitário íntegro revelaram-se excelentes, com rendimentos superiores a $90 \%$, indicando a efetividade da técnica.

O tempo relativamente longo de incubação na fase de préestanização (40 minutos), quando comparado ao tempo de incubação para marcação com o reagente lipofílico de HMPAO- ${ }^{99 \mathrm{~m}} \mathrm{Tc}\left(10\right.$ minutos) ${ }^{11}$ pode ser atribuido ao transporte por difusão passiva do estanho, ao contrário do complexo lipofílico de HMPAO- ${ }^{99 m} \mathrm{Tc}$ que possui alta lipossolubilidade e conseqüente facilidade para atravessar a membrana celular.

De forma comparativa, podemos dizer que o tempo de processamento total envolvido na técnica de pré-estanização é maior que o da técnica do quelante lipofílico de HMPAO- ${ }^{99 \mathrm{~m}} \mathrm{Tc}$. O tempo maior é atribuído às duas fases de incubação (pré-estanização e marcação propriamente dita) envolvidas na técnica de pré-estanização com gluco-estanho, enquanto que na técnica do quelante lipofilico, apenas uma etapa de incubação é requerida e com tempo relativamente mais curto.

Adicionalmente, na técnica de pré-estanização, a presença de duas fases no processo de marcação implica em dois procedimentos de centrifugação/lavagem das células, enquanto que na técnica do quelante 
lipofílico, apenas uma etapa de centrifugação/lavagem é empregada. Desta forma, o tempo total de processamento empregando-se a técnica de préestanização com reagente de glucoheptonato-estanho, conforme observado em nossos estudos, é de aproximadamente 150 minutos, enquanto que na técnica do quelante lipofílico de HMPAO- ${ }^{99 \mathrm{~m}} \mathrm{Tc}$ o tempo total está em torno de 90 minutos, conforme descrito por diversos autores. ${ }^{11,18,16}$ Se por um lado a técnica de pré-estanização apresenta a desvantagem em relação ao tempo de processamento, apresenta a vantagem de ser uma técnica mais barata, já que o reagente liofilizado empregado é de custo inferior ao reagente lipofílico importado.

A utilização do reagente lipofílico de HMPAO também possui desvantagens adicionais. O complexo HMPAO- ${ }^{99 \mathrm{~m}} \mathrm{Tc}$ formado é instável, devendo o composto ser utilizado nos primeiros 30 minutos após a marcação. Além disto, cuidados adicionais devem ser observados durante a marcação do reagente de HMPAO com ${ }^{99 m} \mathrm{Tc}$, relativos à solução de pertecnetato. Esta deverá ser recém-eluída de um gerador que não tenha permanecido por mais de 24 horas sem ser eluído.

Ainda de forma comparativa, com relação aos rendimentos de marcação obtidos, a técnica de pré-estanização possibilitou a obtenção de rendimentos excelentes (superiores a 90.\%) e comparáveis aos rendimentos obtidos com a técnica de marcação utilizando o quelante lipofílico (89,0 \pm $3,2 \%)$.

A introdução de aquecimento a $37^{\circ} \mathrm{C}$ durante a etapa de marcação com tecnécio-99m, não resultou em aumento no rendimento de marcação utilizando-se o reagente de gluco-estanho.

$\mathrm{Na}$ formulação do reagente liofilizado de glucoheptonato-estanho utilizou-se ajuste do $\mathrm{pH}$ em torno de 5,0-5,5, o que provavelmente contribuiu para a estabilidade química do cloreto estanoso da preparação, conforme observado nos estudos de estabilidade realizados por período de 3 meses (Tabela 4). A utilização de pH ligeiramente ácido previne a oxidação do 
cloreto estanoso, o que prejudicaria a sua função de agente redutor, comprometendo a eficiência de marcação e, consequentemente, da imagem cintilográfica na identificação de processos infecciosos e inflamatórios.

Embora não tenha sido realizada a determinação química analítica do estanho $\left(\mathrm{Sn}^{+2}\right)$ no reagente liofilizado, o mesmo mostrou boa estabilidade já que no periodo de 3 meses de armazenamento não foram observadas alterações no rendimento de marcação dos leucócitos. A determinação de $\mathrm{Sn}^{+2}$ na preparação do reagente já vem sendo estudada pelo grupo de Controle de Qualidade do Centro de Radiofarmácia, utilizando-se procedimento polarográfico. A técnica deverá ser implementada na rotina de produção do reagente liofilizado de glucoheptonato-estanho e deverá colaborar para realização de um estudo de estabilidade por período superior a 3 meses.

Atentando para citações literárias sobre meios para ressuspender os leucócitos ${ }^{16,30}$, as quais relatam diminuição da eficiência de marcação quando se utiliza plasma pobre em plaquetas (obtido como sub-produto da separação dos leucócitos), todas as marcações deste estudo foram realizadas utilizando-se solução salina como meio para ressuspender os leucócitos centrifugados. A mesma solução foi utilizada para ressuspender os leucócitos radiomarcados utilizados na obtenção das imagens cintilográficas.

O estudo de distribuição biológica dos leucócitos marcados realizado em coelho evidenciou captação pulmonar, hepática e renal do radiofármaco, conforme esperado, em função da distribuição fisiológica do composto (Figura 1). Distribuição similar foi observada por diversos autores após utilização de leucócitos marcados empregando diferentes técnicas de marcação. ${ }^{26}$

Os leucócitos radiomarcados neste estudo, utilizando técnica de pré-estanização, mostraram-se úteis na identificação do foco de inflamação provocado a partir da injeção de terebentina (Figura 2). A visualização do foco acentua-se após 3 horas da administração, confirmando captação por 
mecanismo seletivo e não por simples aporte sanguíneo no local de inflamação.

O método de marcação de leucócitos estudado mostrou-se reprodutivo, tendo apresentado bons rendimentos e eficácia na identificação de processo inflamatório. Os resultados obtidos encorajam a realização de lotes pilotos de produção (validação do método de produção e controle de qualidade) e a realização de protocolo clínico que possibilite a implantação desta técnica na rotina clínica de investigação de focos de infecção e inflamação em Medicina Nuclear. O método representa ainda uma alternativa viável e custo efetiva, quando comparada aos métodos atualmente disponíveis de marcação de leucócitos.

Os estudos de otimização da marcação de leucócitos utilizando-se o reagente liofilizado de glucoheptonato-estanho produzido, bem como a padronização da técnica de coleta e manipulação do sangue realizadas foram imprescindiveis para orientação futura do cliente usuário do produto na aplicação clínica rotineira. Neste sentido, este trabalho deixa esboçado, a título de contribuição, o modelo de uma bula, com instruções relativas à coleta e manipulação da amostra sanguinea bem como preparo do reagente liofilizado e procedimento de marcação das células que poderá servir de base para composição da bula definitiva do produto para efeito de comercialização (Anexo 1). 


\section{CONCLUSÕES}

De tudo que foi apresentado, podemos concluir a respeito deste trabalho que:

- O reagente liofilizado de glucoheoptnato-estanho produzido mostrouse efetivo e reprodutível na marcação de leucócitos com tecnécio$99 \mathrm{~m}$ com alto rendimento;

- O reagente liofilizado de glucoheptonato-estanho produzido apresentou estabilidade pelo periodo avaliado de 3 meses possibilitando a marcação de leucócitos sem perda do rendimento de marcação;

- O método de pré-estanização representa uma alternativa custo efetiva de marcação de leucócitos com tecnécio-99m apesar de ser mais demorado que o método de marcação por quelante lipofílico de HMPAO- ${ }^{99 \mathrm{~m} T c \text {; }}$

- As imagens cintilográficas obtidas em coelho mostraram a efetividade do composto na identificação seletiva de foco inflamatório e estimulam a realização de protocolo clínico com o composto. 
ANEXO 1

PROPOSTA DE MODELO DE BULA

Glucoheptonato de cálcio- GHA

Conjunto de Reagente Liofilizado de glucoheptonato de sódio-estanho (GHA-SN) para marcação de leucócitos in vitro com ${ }^{99 m} \mathrm{Tc}$

FORMA FARMACÊUTICA E APRESENTAÇÃO

Pó branco liofilizado para uso injetável

Administração intravenosa

Cada conjunto de reagente liofilizado é constituido por 5 frascos, estéreis, livres de pirogênio e acondicionados a vácuo. Cada frasco contém:

\begin{tabular}{|l|l|}
\hline Composição & Quantidade \\
\hline Glucoheptonato de cálcio ( GHA) & $100,0 \mathrm{mg}$ \\
\hline Cloreto estanoso $\left(\mathrm{SnCl}_{2}\right)$ & $263,0 \mu \mathrm{g}$ \\
\hline
\end{tabular}

INDICAÇÃO : O reagente de (GHA-SN) é um eficiente agente para marcação de leucócitos in vitro. O s leucócitos marcados posteriormente são reinjetados proporcionando a obtenção da imagem cintilográfica. Os leucócitos marcados são úteis na detecção de focos de infecção, especialmente abscessos abdominais, investigação de febre de origem desconhecida e na evolução de processos 
inflamatórios não associada com infecção, como por exemplo distúrbio inflamatório intestinal.

\section{INSTRUÇÃO DE PREPARO E CUIDADOS A SEREM TOMADOS PARA MARCAÇÃO DOS LEUCÓCITOS COM O REAGENTE DE GLUCOHEPTONATO -Sn.}

\section{Obtenção do concentrado leucocitário :}

Coletar $50 \mathrm{~mL}$ de sangue venoso em seringa contendo $10 \mathrm{~mL}$ do anticoagulante ACD.

Transferir para um tubo cônico para centrifugação $(50 \mathrm{~mL})$ e adicionar $6 \mathrm{~mL}$ do agente acelerador de hemossedimentação ( Plasmasteril), homogeinizar e aguardar a sedimentação expontânea dos eritrócitos em temperatura ambiente. Após a hemossedimentação de aproximadamente $50 \%$ do sangue coletado, transferir o plasma formado para um tubo cônico $(15 \mathrm{~mL})$, centrifugar o plasma rico em leucócitos e plaquetas por 5 minutos a $1000 \mathrm{rpm}$. Após esta centrifugação, quando então haverá o botão leucocitátio e o plasma rico em plaquetas, desprezar o plasma restando apenas os leucócitos. Caso haja hemácias no botão leucocitário, estas devem ser lisadas através da edição de 5 $\mathrm{mL}$ de água para injetáveis com posterior imediata adição de $5 \mathrm{~mL}$ de solução de $\mathrm{NaCl} 1,8 \%$, submeter as células a nova centrifugação por 5 minutos a 1000 rpm. Esta etapa deve ser repetida até a eliminação total das hemácias.

Uma vez que o concentrado de leucócitos está pronto, ressuspender o mesmo em $1 \mathrm{~mL}$ de solução $\mathrm{NaCl}$ 0,9\% ( solução fisiológica).

Desta suspensão de leucócitos, preparar uma solução das células 1:20 (50 $\mu \mathrm{L}$ de suspensão de leucócitos para $950 \mu \mathrm{L}$ solução fisiológica ). A partir da suspensão 1:20 dos leucócitos realizar o teste de viabilidade celular, tomando uma alíquota da suspensão de leucócitos em lâmina microscópica e adicionando à mesma uma alíquota do corante Azul triplan, aguardar 5 minutos e proceder a visualização microscópica. 


\section{Estanização dos leucócitos}

Dissolver um frasco do reagente liofilizado de glucoheptonato-Sn em $10 \mathrm{~mL}$ de solução salina ( $\mathrm{NaCl} 0,9 \%$ ). Posteriormente adicionar ao concentrado leucocitário $4 \mathrm{~mL}$ do reagente de glucoheptonato - $\mathrm{Sn}$, seguido de incubação em banho-Maria à $37^{\circ} \mathrm{C}$ por 40 minutos. Finda a incubação, centrifugar o composto por 10 minutos a 1000 rpm, desprezar o sobrenadante, e realizar a lavagem do botão leucocitário utilizando $10 \mathrm{ml}$ de solução fisiológica e submetendo-o a nova centrifugação a $1000 \mathrm{rpm}$ por 5 minutos, realizar esta etapa por duas vezes.

\section{Radiomarcação dos leucócitos}

Após a estanização dos leucócitos, adicionar aos mesmos a solução de pertecnetato de sódio com atividade $555 \mathrm{MBq}$ (15 mCi), seguido de incubação por 20 minutos em temperatura ambiente (em local blindado). Terminada a incubação do composto radiomarcado, centrifugar por 10 minutos a $1000 \mathrm{rpm}$.

\section{CONTROLE DE QUALIDADE}

Determinação do rendimento de marcação: Antes da administração dos leucócitos radiomarcados, é necessário verificar o rendimento de marcação, através da medida da atividade do concentrado leucocitário pela atividade do total utilizada:

Eficiência de marcação (\%) : Ativ. Leucócitos/Atividade total x 100

\section{POSOLOGIA}

Atividades recomendadas para um paciente adulto de $70 \mathrm{~kg}$ de peso.

Administrar por via intravenosa $185-370 \mathrm{MBq}(5-10 \mathrm{mCi})$ 
As imagens estáticas dos focos infecciosos ou inflamatórios podem ser iniciadas 1 (uma) hora após a administração dos leucócitos radiomarcados.

\section{ADVERTÊNCIAS E PRECAUÇÕES}

Este produto só pode ser preparado e administrado por profissionais credenciados e autorizados pelas entidades de controle nuclear e deverão ser manipulados em estabelecimentos clínicos especializados. A utilização e transferência do produto marcado e controle de rejeitos radioativos estão sujeitos aos regulamentos dos organismos oficiais competentes. Este radiofármaco deve ser preparado de forma que seja preservada a qualidade radiofarmacêutica. Devem ser tomados os devidos cuidados de assepsia , em conformidade com as normas de Boas Práticas de Fabricação emitidas para produtos farmacêuticos.

\section{INTERAÇÕES COM OUTROS FÁRMACOS}

Alguns medicamentos convencionais podem provocar diminuição do rendimento de marcação dos leucócitos, ou comprometimento da qualidade da imagem cintilográfica. Tal efeito pode ocorrer por ter esses medicamentos os leucócitos como células alvos onde, a produção de fatores quimiotáticos (interleucinas) fica comprometido ou eles atuam fragilizando os leucócitos por desnaturarem determinadas enzimas ou ainda interferindo na resposta quimiotática dos leucócitos.São eles : ciclosporina, AZT, nifidipina ranetidina e sais de ferro.

\section{REAÇÕES ADVERSAS}

A administração de um radiofármaco a um paciente resulta em certa dose de radiação absorvida. Entretanto, somente o uso repetitivo, por longo prazo, pode promover alterações somáticas ou danos genéticos. A administração endovenosa do 
radiofármaco pode causar dor ou irritação localizada no ponto de administração do produto.

\section{ARMAZENAGEM}

O reagente liofilizado de GHA-SN deve ser armazenado sob refrigeração. Não utilizar após a expiração do prazo de validade, que é de 3 meses. Após reconstituição e marcação com ${ }^{99 \mathrm{~m}} \mathrm{Tc}$, o produto deverá ser conservado em temperatura inferior a $25^{\circ} \mathrm{C}$ e utilizado dentro do período de 1 hora. 


\section{REFERÊNCIAS BIBLIOGRÁFICAS}

1. MICHAEL M. GRAHAM and DARLENE F. METTER. Evolution of nuclear medicine training : Past, Present and Future. Journal of Nuclear Medicine. v. 48, n. 2, p.257-268, feb. 2007.

2. W. BECKER and J. MELLER. The role of nuclear medicine in infecction and inflammation. The Lancet Infection Diseases. v.1, p. 326-333, , dec. 2001.

3. HUUB J.J.M. RENNER, OTTO C. BOERMAN, WEM J. G. OYEN, FRANS $H$. M. CORSTENS. Imaging infection/inflammation in the new millennium. European J. of Nucl Med. v. 28, n. 2, p. 241-252, feb. 2001.

4. PILAR ORELLANA B., LORENA RIOS S. , PAULINA GAJARDO P. , ENRIQUE OLEA G. , VALENTINA ORTIZ C. , JULIANA NAGEL S. , CARLOS QUINTANA V. y MARIA CECILIA GIL V. Detccion de actividad en enfermedad de Crohn y Colitis ulcerosa : cintigrafia con leucocitos- Tc-99m glucoheptonato. Rev. Méd. Chile. v. 120, p. 10061010, 1992.

5. MERAL TAYAN ERCAN and LALE KOSTAKOGLU. Radiopharmaceuticals for the visualization of infectious and inflammatory lesions. Current Pharmaceutical Design. v.6, p.1159-1177, 2000.

6. JAMES H. THRALL and HARVEY A. ZIESSMAN. Medicina Nuclear- $2^{a}$ ed, p. 162-191,Editora Guanabara -Coogan, 2003.

7. S.C. SRIVASTAVA, R. F. STRAUB, R.R. MODESTO and W.W. SHREEVE. A stannous glucoheptonate kit method for $99 \mathrm{~m}-$ Tc labeling of 
leucocytes and platelets. J. Labeled Compounds Radiopharm. v. 16, p. 38-40, 1989.

8. SURESH C. SRIVASTAVA and RITA F. STRAUB. Blood cell labeling with $99 \mathrm{~m}-\mathrm{Tc}$ : Progress and Perspectives- Seminars in Nuclear Medicine, v. XX, n. p. 41-51, jan.1990.

9. JAMES A. PONTO. The A.A.P.M / RSNA Physics Tutorial for Residents. Imaging \& Therapeutic Technology . v.18, n. 6, p.1395-1404, 1998.

10. JONATHAN R. DILVORTH and SUZANNE J. PARROTT. The Biomedical chemistry of technetium and rhenium. Chemical Society Reviews. v.2, p.43-55, 1998.

11.M. ROCA, J. MARTIN-COMIN, W. BECKER, M. BARDO-FILHO, B. GUTFILEN, A. MOISAN, M. PETERS, E. PRATS, M. RODRIGUES, C SAMPSON, A. SIGNORE, H. SINZINGER, M. THAKUR. A consensus protocol for white blood cells labelling with technetium-99m hexamethylpropylene amine oxime. Eur j Nucl Med . v.25, n.7, p. 797799, july 1998.

12. J.C. HUNG, S. CHOWDHURY, D. W. MAHONEY and B. P. MULLAN. Radiolabelled mixed leukocytes and pure granulocytes with stabilized 99m-Tc - exametazime. Nuclear Medicine Communications. v. 19, n.10, p.981-987, 1998.

13.I. TAGLIABUE, C. MAJOLI, U. PAJORO, M. MUSARRA, C. DI LEO A.DEL SOLE, A. BESTETTI, G. L. TAROLO.Labelled leukocytes for diagnosis of infectious diseases. Our experience in labelling and clinical usefulness. Minerva Med. v.91, n. 11-12, p.267-74, 2000.

14. STEFAN GRATZ, MD, HUUB J.J.M. RENNEN, OTTO C. BOERMAN, WIM J.G. OYEN, PETER MAST, THOMAS M. BEHR and FRANS H. M. CORSTENS. 99mTc- HMPAO- labeled autologous versus heterologous 
leukocytes for imaging infection. The Journal of Nuclear Medicine. v.43, n.7, p.918-24, july 2002.

15. HAROLD B. ANSTALL and R. EDWARD COLEMAN. Donor-leukocyte imaging in granulocytopenic Patients with suspected abscesses: Concise Communication. J Nucl Med. v.23, n.4, p.319-21, 1982.

16. JOSEPH MARTIN-COMIN, VALBERT NASCIMENTO CARDOSO, PEDRO PLAZA and MANOEL ROCA. Hanks balanced salt solution : an alternative resuspension medium to label autologous leukocytes. Experience in inflammatory bowel disease. Braz. Arch. Biol. Technol. v.45, p.39-44, sept.2002.

17 TAMÁS GYORKE, LÁSZLÓ, DUFFEK, KATALIN BÁRTFAI, ERNÓ MAKÓ, KINGA KARLINGER, ÁDÁM MESTER, ZSOLT TARJÁN. The role nuclear medicine in inflammatory bowel disease. A rewiew with experiences of aspecific bowel activity using immunoscintigraphy with ${ }^{99 m} \mathrm{Tc}$ anti-granulocytes antibodies. European Journal of Radiology. v. 35, p. $183-92,2000$.

18 P.A.G. HAMMERSLEY and A.T. NKOHKWO. Studies on white blood cell labelling : ${ }^{99 \mathrm{~m}} \mathrm{Tc}-\mathrm{HMPAO}$ preferentially labels granulocytes. Nuclear Medicine Communications. v. 22, p.981-86, 2001.

19 CONNY J van der LAKEN, OTTO C. BOERMAN, WIM J. G. OYEN, MARJO T. P. Van de Ven, JOS W. M. Van der MEER, FRANS H.M.CORSTENS. Scintigraphic detection of infection and inflammation: new developments with special emphasis on receptor interaction. Eur $\mathbf{J}$ Nucl Med, v. 25, p.535-546, 1998.

20 R.E.WEINER, M.L. THAKUR. Imaging infection / inflammation. The Quarterly Journal of Nuclear Medicine. v.43, n.1, p.2-8,March 1999. 
21 A.M.PETERS. Nuclear Medicine imaging in fever of unknown origin. The Quarterly Journal of Nuclear Medicine.v.43, n.1, p.61-73,March 1999.

22 A.SIGNORE, A. ANNOVAZZI, M. CHIANELLI, F. CORSETTI, C. VAN de WIELE, R.N. WATHERHOUSE, F.SCOPINARO. Peptide radiopharmaceutical for diagnosis and therapy. European Journal of Nuclear Medicine.v.28, n.10, October 2001.

23 T.A.F.EL-MAGHRABY, H.M. MOUSTAFA, E.K.J.PAUWELS. Nuclear Medicine methods for evaluation of skeletal infection among other diagnostic modalities. The Quarterly Journal of Nuclear Medicine and Molecular Imaging. v.50, n.3, p.167-192, 2006.

24 A.BENITEZ, M. ROCA, J. MARTIN-COMIN. Labeling of antibiotics for infection diagnosis. The Quarterly Journal of Nuclear Medicine and Molecular Imaging. v.50, n.2, p.147-52. 2006.

25 S.M. OKARVI. Recent development in ${ }^{99 \mathrm{~m}} \mathrm{Tc}$ - labelled peptide-based radiopharmaceutical: An overview. Nuclear Medicine Communications, v.20, p. 1093-1112, 1999.

26 M. CHIANELLI, S.J.MATHER, J..MARTIN-COMIN and A. SIGNORE. Radiopharmaceuticals for the study of inflammatory process : A review. Nuclear Medicine Communications. v.18, p. 437-455, 1997.

27 A.LUPETTI, E. K. J. PAUWELS, P.H. NIBBERING, M.M. WELLING. ${ }^{99 \mathrm{~m}} \mathrm{Tc}$ - Antimicrobial peptides:promising candidates for infection imaging. The Quarterly Journal of Nuclear Medicine. v. 47, p. 238-45, 2003.

28 S.L. KIPPER. The role of radiolabeled leukocyte imaging in the management of patients with acute appendicitis. The Quarterly Journal of Nuclear Medicine. v.43, n.1, p. 83-92, 1999. 
29 C.B. SAMPSON. Interference of patient medication in the radiolabeling of white blood cell: An update. Nuclear Medicine Communications. v.19, p. $529-533$.

30 V.N. CARDOSO, P.J.L. PLAZA, M. ROCA, F. ARMERO and J. MARTINCOMIN. Assessment of inflammatory bowel disease by using two different ${ }^{99 \mathrm{~m}} \mathrm{Tc}$ leucocyte labeling methods. Nuclear Medicine Communications. v. 23 , p. $715-720$.

31 ROSS HANNA, TERRY BRAUN, ALEX LEVENDEL, and FRED LOMAS. Radiochemistry and biostability of autologous leucocytes labelled with ${ }^{99 m}$ Tc-stannous colloid in whole blood. Eur j Nucl Med. v. 9, p. 216-219, 1984.

32 BOERMAN, O.C.; STOR, G. ; OYEN, W.J.G.; VAN BLOOIS, L.; VAN DER MEER, J.W.M.; CLAESSENS, R.A.; CORSTENS, F. H. M. Sterically stabilized liposomes labeled with 111 In to image focal infection in rats. J. Nucl .Med. ,v.36, p.1639-1644, 1995.

33 HNATOWICH, D.; VIRZI , F.; RUSCKOWSKI, M. Investigation of avidin and biotin for imaging investigation. J. Nucl. Med., v.28, p.1294-1302, 1987.

34 PETERS, A. M. The utility of $99 \mathrm{~m}$ TC-HMPAO- leukocytes for imaging infection. Semin. Nucl.Med. v.24, p. 110-127, 1994.

35 DATZ, F. L. Indium-111 labeled leukocytes for the detection of infection: current status. Semin. Nucl. Med., v.24, p.92-109, 1994.

36 TSAN, M. F. Mechanism of gallium- 67 accumulation in inflammatory lesions. J.Nucl.Med., v.26, p.88-92, 1985.

37 VAN DER LAKEN, C. J. ; BOERMAN, O.C.; OYEN, W.J.G.; VAN DER VEM, M.T.P.; VAN DER MEER, J.W.M.; CORSTENS, F.H.M.

Scintigraphy detection of infection and inflammation: new developments 
with special emphasis on receptor interaction. Eur. J.Nucl. Med., v.25, n.5, p. $535-546,1998$

38 ATHENS, J.W., MAUER, A. M., ASHENBRUCKER, H., CARTWRIGHT, G.E., WINTROBE, M.M. Blood. V.14, p.303-33, 1959.

39 WINKELMAN, J., COLLICA, C. J., SANDLER, S.G. Ann. J. Roentgenol, v. 103, p. $881-5,1968$.

40 THAKUR, M.L., LAVENDER, J.P., ARNOT,R.N., SILVESTER, D.J., SEGAL, A.N. J. Nucl. Med. v.18, p.1014-21, 1977.

41 THAKUR, M.L., COLERMAN, R.E.WELCH, M.J. Lab.Clin. Med. v. 89, p.217-28, 1977.

42 MCAFFE, J.G., THAKUR, M.L Survey of radioactive agents for the in vitro labelling of phagocitic leukocytes. I. Soluble agents. II. Particles. J. Nucl. Méd. V.17, p.480-492, 1976.

43 PETERS, A. M., DANPURE, H.J., OSMAN, S. Preliminary clinical experience with 99m-Tc-haxamethylpropylene-aminoxime for labelling leukocytes and imaging infections. Lancet, v.2, p.945-949, 1986.

44 DATZ, F.L. Indium-111- labeled leukocytes for the detection of infection : current status. Semin. Nucl. Med. v.24, p.92-109, 1994.

45 DATZ, F.L., THORNE, D.A. Effect of chronicity of infection on the sensitivity of the In-111-labeled leukocytes scan. AJR Am J. Roentgenol. v.147, p.809-812, 1986.

46 BABAICH, J.W, SOLOMON, H., PIKE, M.C., KROON, D. , GRAHAM, W. ABRAMS, M.J., TOMPKINS, R.G., RUBIN, R.H., FISCHMAN. A.J. Technetium-99m- labeled hydrazino nicotinamide derivatized peptide 
analogs for imaging focal sites of bacterial infection. J. Nucl. Med. v.34, p.1964-1974, 1993. 